\title{
ASPECTOS TERAPÊUTICOS DE COMPOSTOS DA PLANTA Cannabis sativa
}

\author{
Káthia Maria Honório \\ Instituto de Física de São Carlos, Universidade de São Paulo, CP 369, 13560-570 São Carlos - SP \\ Agnaldo Arroio e Albérico Borges Ferreira da Silva* \\ Departamento de Química e Física Molecular, Instituto de Química de São Carlos, Universidade de São Paulo, CP 780, \\ 13560-590 São Carlos - SP
}

Recebido em 26/10/04; aceito em 6/6/05; publicado na web em 8/12/05

\begin{abstract}
THERAPEUTICAL ASPECTS OF COMPOUNDS OF THE PLANT Cannabis sativa. Several cannabinoid compounds present therapeutic properties, but also have psychotropic effects, limiting their use as medicine. Nowadays, many important discoveries on the compounds extracted from the plant Cannabis sativa (cannabinoids) have contributed to understand the therapeutic properties of these compounds. The main discoveries in the last years on the cannabinoid compounds were: the cannabinoid receptors $\mathrm{CB}_{1}$ and $\mathrm{CB}_{2}$, the endogenous cannabinoids and the possible mechanisms of action involved in the interaction between cannabinoid compounds and the biological receptors. So, from the therapeutical aspects presented in this work, we intended to show the evolution of the Cannabis sativa research and the possible medicinal use of cannabinoid compounds.
\end{abstract}

Keywords: Cannabis sativa; cannabinoids; therapeutic properties.

\section{INTRODUÇÃO}

Uma planta que apresenta grande potencial terapêutico, apesar de suas propriedades psicotrópicas, é a Cannabis sativa L. (Figura 1). Esta planta vem sendo utilizada, há séculos, pela humanidade para diversos fins, tais como, alimentação, rituais religiosos e práticas medicinais ${ }^{1}$. O primeiro relato medicinal da planta Cannabis foi atribuído aos chineses, que descreveram os potenciais terapêuticos desta planta no Pen-Ts'ao Ching (considerada a primeira farmacopéia conhecida do mundo) há 2000 anos atrás. Os assírios, cerca de 300 anos atrás, consideravam a Cannabis como o principal medicamento de sua farmacopéia e a chamavam de acordo com seu uso: qunnabu, quando a planta era utilizada em rituais religiosos; azallu, um termo medicinal assim como hemp; gan-zi-gun$n u$, o qual significava "a droga que extrai a mente"2.
Planta

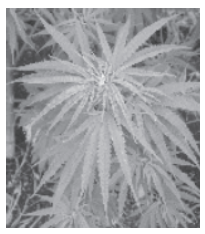

Cannabis sativa
Principal substância bioativa

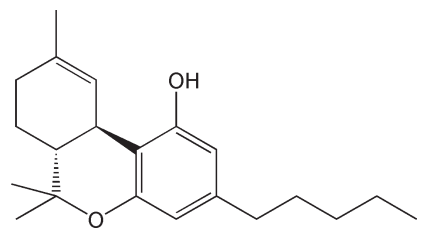

$\Delta^{9}-\mathrm{THC}$
Figura 1. A planta Cannabis sativa e a principal substância bioativa extraída $\left(\Delta^{9}-T H C\right)$

A Cannabis sativa é um arbusto da família Moraceae, conhecido pelo nome de "cânhamo da Índia", que cresce livremente em várias partes do mundo, principalmente nas regiões tropicais e temperadas. É uma planta dióica, pois tem espécimes masculinas e femininas. A planta masculina geralmente morre após polinizar a planta feminina. Além de Cannabis sativa, outros nomes atribuídos aos produtos da Cannabis são marijuana, hashish, charas,

*e-mail: alberico@iqsc.usp.br bhang, ganja e sinsemila. Hashish (haxixe) e charas são os nomes dados à resina seca extraída das flores de plantas fêmeas, que apresenta a maior porcentagem de compostos psicoativos (de 10 a $20 \%$ ). Os termos ganja e sinsemila são utilizados para definir o material seco encontrado no topo das plantas fêmeas, contendo cerca de 5 a $8 \%$ de compostos psicoativos. Bhang e marijuana são preparações com menor conteúdo ( 2 a 5\%) de substâncias psicoativas extraídas do restante da planta ${ }^{3}$. O termo maconha é utilizado no Brasil para os preparados da Cannabis sativa.

A concentração de compostos psicoativos (canabinóides) na Cannabis é uma função de fatores genéticos e ambientais, mas outros fatores que causam variações no conteúdo psicoativo da planta devem ser considerados, tais como, o tempo de cultivo (maturação da planta) e tratamento da amostra (secagem, estocagem, extração e condições de análise $)^{4}$. Nas últimas décadas, muitas descobertas importantes sobre a Cannabis foram realizadas, mas muitos mitos e incertezas ainda persistem. Uma parte bem arraigada do folclore sobre a Cannabis é que somente a planta fêmea fornece a resina ativa, mas as plantas (macho e fêmea) produzem, aproximadamente, as mesmas quantidades de canabinóides e possuem o mesmo grau de atividade ${ }^{4}$. A convicção de que somente plantas fêmeas contêm a resina ativa foi atribuída, provavelmente, devido à prática agrícola de eliminar plantas-macho das plantações de Cannabis, a fim de prevenir a fertilização.

O uso medicinal da Cannabis hoje é permitido em alguns estados americanos e em países como Holanda e Bélgica, para aliviar sintomas relacionados ao tratamento de câncer, AIDS, esclerose múltipla e síndrome de Tourette (que causa movimentos involuntários $)^{5-7}$. Muitos oncologistas e pacientes defendem o uso da Cannabis, ou do $\Delta^{9}$-THC (seu principal componente psicoativo), como agente antiemético mas, quando comparada com outros agentes terapêuticos, a Cannabis tem um efeito menor do que os fármacos já existentes ${ }^{5-7}$. Contudo, seus efeitos podem ser aumentados quando associados com outros antieméticos. Desta maneira, o uso da Cannabis na quimioterapia pode ser eficiente em pacientes apresentando náuseas e vômitos, sintomas que não são controlados com outros medicamentos ${ }^{8}$. 
A alta pressão intra-ocular é um dos fatores de risco para desenvolvimento de glaucoma e a planta Cannabis pode agir diminuindo esta pressão, mas este efeito é de curta duração e só é conseguido com altas doses da planta ${ }^{9}$. Apesar do glaucoma ser uma das indicações mais citadas para o uso da Cannabis, a droga só é utilizada em casos mais graves ${ }^{10,11}$.

Os efeitos adversos da Cannabis podem ser divididos em duas categorias: os efeitos do hábito de fumar a planta e os causados pelas principais substâncias isoladas (canabinóides). O fumo crônico da maconha provoca alterações das células do trato respiratório e aumenta a incidência de câncer de pulmão entre os usuários ${ }^{10}$. Um dos efeitos associados ao longo tempo de exposição aos canabinóides é a dependência dos efeitos psicoativos com a cessação do uso. Os sintomas da dependência dos efeitos psicotrópicos da planta incluem agitação, insônia, irritabilidade, náusea e câimbras ${ }^{5}$. Pesquisas também mostram que a Cannabis não causa dependência física (como cocaína, heroína, cafeína e nicotina) e que a suspensão do uso não causa síndrome de abstinência (como o álcool e a heroína). Seu uso prolongado em certas circunstâncias causa dependência psicológica, e pode levar ao consumo de outras drogas. Por ser uma poderosa droga psicotrópica e alucinogênica, seu uso indiscriminado é perigoso ${ }^{12}$.

A potencialidade medicinal da Cannabis está ligada ao grande número de substâncias químicas que já foi encontrado em amostras desta planta, como ilustra a Tabela 1, sendo a principal classe a dos canabinóides. O termo canabinóides foi atribuído ao grupo de compostos com 21 átomos de carbono presentes na Cannabis sativa, além dos respectivos ácidos carboxílicos, análogos e possíveis produtos de transformação. Os compostos canabinóides podem ser classificados como terpenofenóis e não foram isolados de qualquer outra espécie vegetal ou animal ${ }^{1}$. A estrutura típica de um canabinóide está representada na Figura 2, indicando os principais sistemas de numeração encontrados na literatura.

\section{CANABINÓIDES}

O primeiro caso comprovado de isolamento, em forma pura, de um princípio ativo da Cannabis, o $\Delta^{9}$-tetraidrocanabinol ou simplesmente $\Delta^{9}$-THC, foi reportado, em 1964, por Gaoni e Mechoulam ${ }^{1}$. Devido ao grande interesse nos efeitos causados pelos compostos extraídos da Cannabis, vários estudos têm sido realizados com o objetivo de identificar possíveis relações entre estrutura química e atividade biológica apresentada por estes com-

(a)

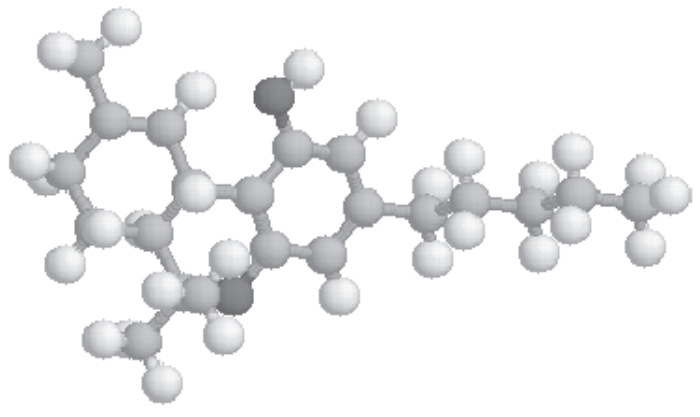

(b)

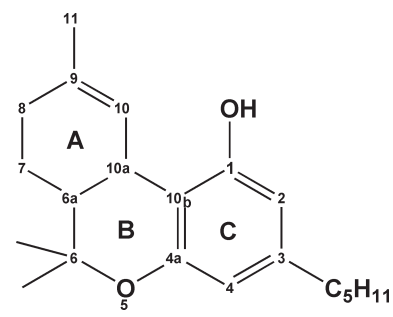

(c)

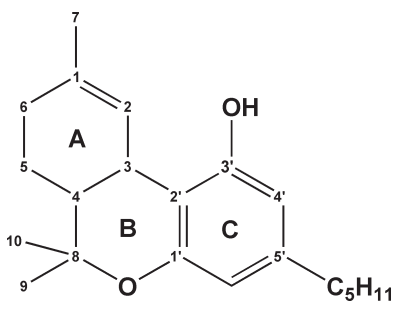

Figura 2. (a) Estrutura 3D de um canabinóide, (b) e (c) dois sistemas de numeração utilizados para os compostos canabinóides

Tabela 1. Classes de compostos encontrados na planta Cannabis sativa

\begin{tabular}{lccc}
\hline Classe & $\begin{array}{c}\text { Número de compostos } \\
\text { encontrados na planta }\end{array}$ & $\begin{array}{c}\text { Cúmero de compostos } \\
\text { encontrados na planta }\end{array}$ \\
\hline Canabinóides & 61 & Cetonas simples & 13 \\
Canabigerol (CBG) & 6 & Ácidos simples & 20 \\
Canabicromeno (CBC) & 4 & Ácidos graxos & 12 \\
Canabidiol (CBD) & 7 & Ésteres e lactonas simples & 13 \\
$\Delta^{1(9)}$-THC & 9 & Esteróides & 11 \\
$\Delta^{2(8)}$-THC & 2 & Açúcares e análogos & 34 \\
Canabiciclol (CBL) & 3 & Monossacarídeos & 13 \\
Canabielsoin (CBE) & 3 & Dissacarídeos & 2 \\
Canabinol (CBN) & 6 & Polissacarídeos & 5 \\
Canabinodiol (CBND) & 2 & Ciclitóis & \\
Canabitriol (CBT) & 6 & Amino-açúcares & 12 \\
Outros canabinóides & 13 & Terpenos & 2 \\
Compostos Nitrogenados & 20 & Monoterpenos & 103 \\
Bases quartenárias & 5 & Sesquiterpenos & 58 \\
Amidas & 1 & Diterpenos & 38 \\
Aminas & 12 & Triterpenos & 1 \\
Alcalóides espermidinas & 2 & Mistura de terpenóide & 2 \\
Aminoácidos & 18 & Fenóis não-canabinóides & 4 \\
Proteínas, glicoproteínas e enzimas & 9 & Glicosídeos Flavonóide & 16 \\
Hidrocarbonetos & 50 & Vitaminas & 19 \\
Álcoois simples & 7 & Pigmentos & 1 \\
Aldeídos simples & 12 & Total & 2 \\
\hline
\end{tabular}


postos. Na década de 70, muitos compostos canabinóides foram isolados e sintetizados e as principais rotas de síntese e biossíntese foram elucidadas ${ }^{1}$.

A obtenção sintética de compostos canabinóides é uma área de grande interesse. Algumas indústrias e laboratórios acadêmicos desenvolveram fármacos baseados nas estruturas de compostos canabinóides, mas uma das dificuldades encontradas foi o isolamento dos efeitos psicotrópicos, o que impossibilitou o uso medicinal destes compostos ${ }^{6}$. Uma exceção foi o Nabilone (Figura 3), uma potente substância do tipo canabinóide, que apresentou sucesso em sua utilização como agente antiemético no Reino Unido e em outros países ${ }^{13}$.

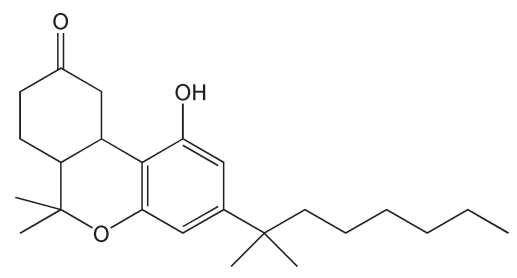

Figura 3. Estrutura química do Nabilone

Os compostos canabinóides que apresentam atividade biológica reconhecida são: o $\Delta^{9}$-THC, utilizado como antiemético e como estimulante do apetite; o $\Delta^{8}$-THC, considerado menos caro que o $\Delta^{9}$-THC para obtenção e, segundo estudos de propriedades antieméticas, tão ativo quanto o $\Delta^{9}$-THC, mas não é comercializado por razões puramente comerciais ${ }^{13}$. Apesar das aplicações citadas acima, os canabinóides apresentam um largo espectro de aplicação medicinal ${ }^{5}$.

Em relação ao metabolismo, os canabinóides e seus metabólitos são distribuídos por todo o organismo e já foram encontrados em fezes, plasma, urina e alguns órgãos. Atualmente, foram alcançados grandes progressos na compreensão do mecanismo de distribuição, armazenagem e eliminação dos canabinóides e seus metabólitos ${ }^{1}$. Estas informações contribuem para melhor compreensão dos efeitos causados pela utilização da maconha, uma das preparações da Cannabis sativa mais utilizada no mundo ocidental.

\section{Potenciais terapêuticos dos canabinóides}

A aplicação terapêutica dos canabinóides é um tema muito controverso pois, apesar das propriedades terapêuticas, estes compostos apresentam também efeitos psicotrópicos, considerados os principais vilões no uso medicinal desta classe de compostos. Dois exemplos de fármacos desenvolvidos com base em compostos canabinóides são o Marinol ${ }^{\circledast}$ (Dronabinol, (-)- $\Delta^{9}$-THC), desenvolvido pelo laboratório Roxane (Columbus - EUA) e o Cesamet ${ }^{\circledR}$ (Nabilone), desenvolvido pelo laboratório Eli Lilly (Indianápolis EUA) e agora liberado para uso terapêutico no Reino Unido ${ }^{14,15}$. As estruturas dos compostos canabinóides presentes nestes fármacos podem ser visualizadas na Figura 4. Estes medicamentos são comercializados para controle de náuseas produzidas durante tratamentos de quimioterapia e como estimulantes do apetite, durante processos de anorexia desenvolvidos em pacientes com síndrome da imunodeficiência adquirida (AIDS) ${ }^{16}$.

Embora os canabinóides exerçam efeitos diretos sobre um determinado número de órgãos, incluindo os sistemas imunológico e reprodutivo, os principais efeitos farmacológicos observados estão relacionados ao sistema nervoso central ${ }^{7}$. Alguns exemplos das aplicações terapêuticas dos canabinóides são efeito analgésico ${ }^{17-19}$, controle de espasmos em pacientes portadores de esclerose múlti-

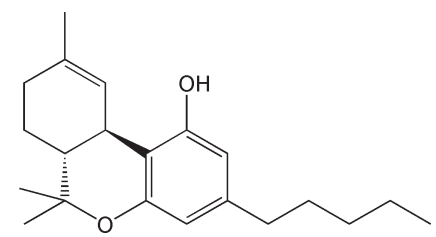

$\operatorname{Marinol}^{\circledR}\left(\Delta^{9}-\mathrm{THC}\right)$

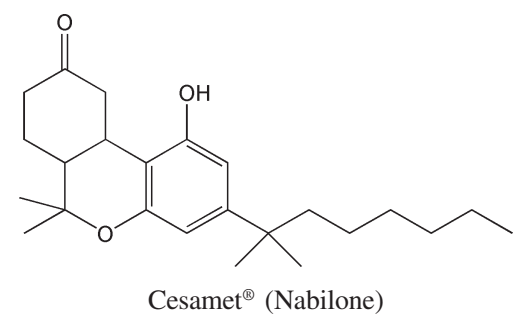

Figura 4. Compostos canabinóides presentes nos fármacos Marinol $^{\circledR} e$ Cesamet $^{\oplus}$

pla $^{20}$, tratamento de glaucoma ${ }^{21}$, efeito broncodilatador ${ }^{22}$, efeito anticonvulsivo ${ }^{23,24}$, etc.. Alguns efeitos colaterais podem acompanhar os efeitos terapêuticos citados acima, tais como, alterações na cognição e memória, euforia, depressão, efeito sedativo e ou$\operatorname{tros}^{25}$.

Informações sobre o uso clínico dos canabinóides podem ser obtidas a partir do mecanismo de ação destes compostos no cérebro, especialmente quando não existem dados experimentais que avaliem, adequadamente, o valor medicinal dos canabinóides ${ }^{26}$. A seguir, são discutidos alguns fatores relacionados ao mecanismo de ação dos canabinóides.

\section{Atividade analgésica dos canabinóides}

Uma atividade biológica apresentada pelos compostos canabinóides e muito estudada é a analgésica. Os analgésicos pertencem a uma das classes de fármacos mais vendidas no mundo, responsável por cifras da ordem de centenas de bilhões de dólares ${ }^{27}$. Na história, diversos compostos alucinógenos, como o ópio, foram relacionados à atividade analgésica. Em relatos científicos, a morfina aparece em 1803 e tem sua estrutura definida em $1925^{28}$. Este foi o ponto de partida para modificações estruturais nas moléculas de canabinóides, visando aumentar a atividade analgésica e diminuir a dependência causada pela droga ${ }^{29}$. Alguns compostos canabinóides modificados chegaram a apresentar um potencial analgésico cerca de 6000 vezes superior ao da morfina ${ }^{30}$.

$\mathrm{Na}$ Antiguidade, e até recentemente, a Cannabis foi empregada para tratar uma variedade de doenças humanas. Uma importante área de pesquisa é o estudo do efeito analgésico dos compostos canabinóides. Alguns estudos laboratoriais relatam que alguns compostos canabinóides possuem eficácia e potência similares à morfina, inclusive alguns com potência 200 vezes maior que a morfina, supostamente mediadas pela inibição da neurotransmisão nas vias nociceptivas ${ }^{31}$. Porém, a utilização destes canabinóides como analgésicos não é proliferada devido ao efeito psicotrópico apresentado por eles e, também, às questões ainda não compreendidas sobre o mecanismo de ação destes compostos ${ }^{32}$.

\section{Mecanismo de ação dos canabinóides}

Como citado anteriormente, o estudo sistemático da Cannabis sativa e de seus principais componentes (canabinóides) iniciou-se na década de 60, principalmente como resultado das sérias impli- 
cações sociais relacionadas à esta planta. O isolamento, a elucidação das estruturas, a estereoquímica, a síntese, o metabolismo, a farmacologia e os efeitos fisiológicos dos canabinóides estenderamse durante os anos 80 e 90, realizando-se a identificação e clonagem dos receptores canabinóides específicos (CBRs), localizados no sistema nervoso central $\left(\mathrm{CB}_{1}\right)$ e no sistema periférico $\left(\mathrm{CB}_{2}\right)$, além da identificação dos ligantes canabinóides endógenos ${ }^{3}$. Assim, a partir destas descobertas, foi possível entender alguns aspectos importantes relacionados ao mecanismo de ação dos canabinóides.

\section{Receptores canabinóides}

Durante a década de 80 formulou-se a hipótese de que os compostos canabinóides atuariam via um conjunto farmacologicamente distinto de receptores ${ }^{33}$. Até o momento, dois subtipos de receptores canabinóides foram identificados: $\mathrm{CB}_{1}$ e $\mathrm{CB}_{2}{ }^{33}$. Em 1986, Howlett e colaboradores $^{34}$ demonstraram que o $\Delta^{9}$-THC inibia a enzima intracelular adenilato ciclase e que tal inibição só ocorria na presença de um complexo de proteínas-G, ou seja, na presença de um receptor canabinóide, o qual é um membro típico da maior família conhecida de receptores: receptores acoplados às proteínas-G. Acredita-se que os dois receptores canabinóides, $\mathrm{CB}_{1}$ e $\mathrm{CB}_{2}$, são os responsáveis por muitos efeitos bioquímicos e farmacológicos produzidos pela maioria dos compostos canabinóides ${ }^{33}$. Porém, ainda não são conhecidas as diferenças funcionais entre os dois tipos de receptores, mas as diferenças estruturais aumentam esta possibilidade ${ }^{26}$. Os receptores canabinóides $\mathrm{CB}_{1}$ e $\mathrm{CB}_{2}$ são, particularmente, abundantes em algumas áreas do cérebro ${ }^{26}$, como ilustra a Figura 5.

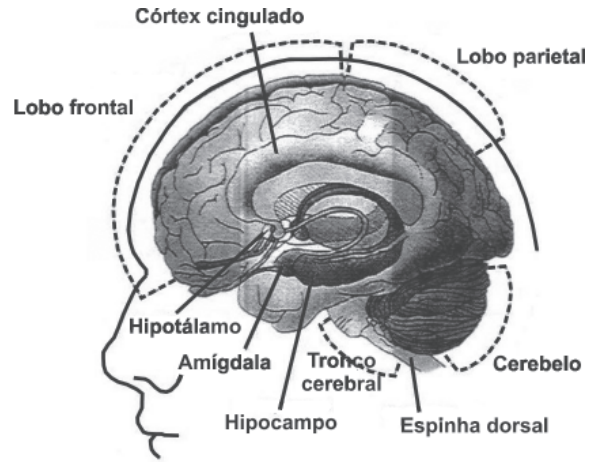

Figura 5. Algumas regiões do cérebro onde os canabinóides atuam. Adaptado da ref. 26

A biologia e o comportamento associados às áreas do cérebro ilustradas na Figura 5 são consistentes com os efeitos comportamentais produzidos pelos canabinóides (Tabela 2). A maior densidade de receptores é encontrada em células dos gânglios basais, envolvidas nos movimentos de coordenação do corpo ${ }^{26}$. Os receptores $\mathrm{CB}_{1}$ também são abundantes no cerebelo, região responsável pela coordenação dos movimentos do corpo; no hipocampo, responsável pela aprendizagem, memória e resposta ao stress e, no córtex cerebral, responsável pelas funções cognitivas ${ }^{26}$.

As células do organismo respondem de diversas formas quando um ligante interage com o receptor canabinóide. Na Figura 6 estão representados alguns processos desencadeados quando um ligante interage com um receptor canabinóide. O primeiro passo é a ativação das proteínas- $\mathrm{G}$, as primeiras componentes no processo de transdução de sinais, e isto leva a mudanças em várias componentes intercelulares, por ex.: abertura ou bloqueio dos canais de cálcio e potássio, o que ocasiona mudanças nas funções celula$\mathrm{res}^{26}$. Os receptores canabinóides estão inseridos na membrana celular, onde estão acoplados às proteínas-G e à enzima adenilato
Tabela 2. Regiões do cérebro onde os receptores canabinóides são abundantes ou moderadamente concentrados e as funções associadas a estas áreas

Regiões do cérebro nas quais os receptores canabinóides são abundantes

\begin{tabular}{ll}
\hline Região do cérebro & Funções associadas à região \\
\hline Gânglios basais & Controle de movimentos \\
Cerebelo & Coordenação dos movimentos do corpo \\
Hipocampo & Aprendizagem, memória, stress \\
Córtex cerebral & Funções cognitivas \\
\hline
\end{tabular}

Regiões do cérebro nas quais os receptores canabinóides estão moderadamente concentrados

Região do cérebro Funções associadas à região

Hipotálamo

Funções de manutenção do corpo (regulação da temperatura, balanço de sal e água, função reprodutiva)

Amígdala Espinha dorsal Tronco cerebral Resposta emocional, medo Sensação periférica, incluindo dor Sono, regulação da temperatura, controle motor

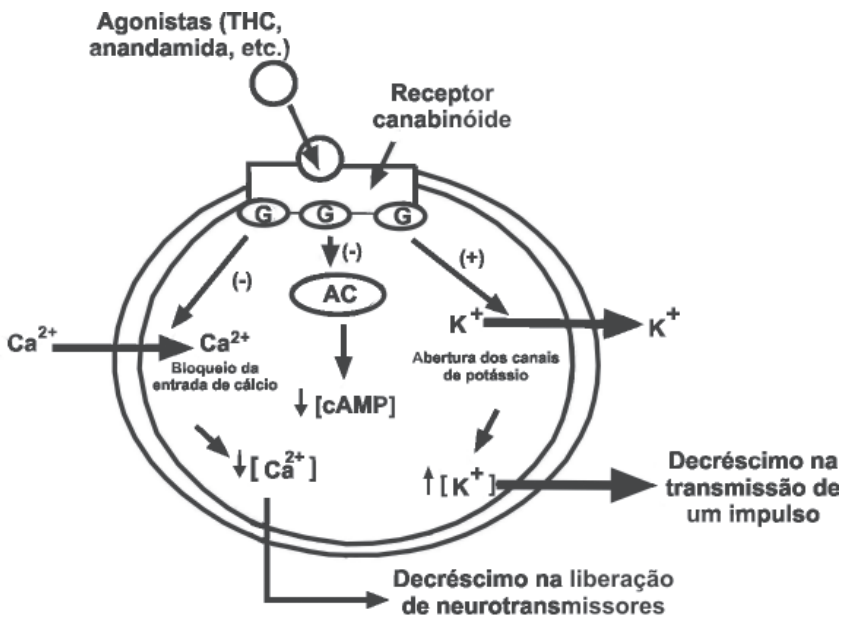

Figura 6. Reações intracelulares que ocorrem quando agonistas interagem com os receptores canabinóides $C B_{1}$ e $C B_{2}$. Adaptado da ref. 26

ciclase (AC). Os receptores são ativados quando interagem com ligantes, tais como anandamida ou $\Delta^{9}$-THC, e a partir desta interação, uma séria de reações ocorre, incluindo inibição da AC, o que diminui a produção de cAMP (as atividades celulares dependem da enzima adenosina monofosfato cíclica - cAMP); abertura dos canais de potássio $\left(\mathrm{K}^{+}\right)$, diminuindo a transmissão de sinais e fechamento dos canais de cálcio $\left(\mathrm{Ca}^{+2}\right)$, levando a um decréscimo na liberação de neurotransmissores. Estes canais podem influenciar na comunicação celular ${ }^{26}$.

O resultado final da interação com o receptor canabinóide depende do tipo de célula, ligante e de outras moléculas que podem competir pelos sítios de ligação deste receptor. Existem vários tipos de agonistas para os receptores canabinóides, e estes podem ser classificados de acordo com dois fatores: a potência de interação com o receptor canabinóide (esta potência determina a dose efetiva do fármaco) e, a eficácia, que determina a extensão máxima do sinal que estes fármacos transmitem às células. A potência e a eficácia do $\Delta^{9}$-THC são relativamente menores quando comparadas 
às de alguns canabinóides sintéticos. Na verdade, compostos sintéticos são, geralmente, mais potentes e eficazes que os agonistas endógenos ${ }^{26}$.

Como citado anteriormente, os receptores canabinóides $\mathrm{CB}_{1} \mathrm{e}$ $\mathrm{CB}_{2}$ são bastante similares, mas não tão similares quanto outros membros de muitas famílias de receptores. As diferenças entre $\mathrm{CB}_{1}$ e $\mathrm{CB}_{2}$ indicam que deveriam existir substâncias terapêuticas que atuariam somente sobre um ou outro receptor e, assim, ativariam ou bloqueariam o receptor canabinóide apropriado ${ }^{35}$. Apesar das diferenças entre os receptores canabinóides $\mathrm{CB}_{1}$ e $\mathrm{CB}_{2}$, a maioria dos compostos canabinóides interage de forma similar na presença de ambos receptores ${ }^{36}$. A busca por compostos que se liguem a apenas um ou outro receptor canabinóide é uma forma utilizada há vários anos para obter compostos com efeitos medicinais específicos ${ }^{36}$.

\section{Canabinóides endógenos}

Para cada receptor biológico (neste caso, um receptor cerebral), provavelmente existe um agonista endógeno, isto é, um composto produzido naturalmente pelo organismo e que interage com o receptor. Duas questões importantes sobre estes ligantes endógenos estão relacionadas ao local no organismo onde eles são produzidos e qual seria a função natural deles. Alguns compostos endógenos que se ligam seletivamente aos receptores canabinóides têm sido estudados e os que chamam mais atenção, apesar de suas propriedades fisiológicas não serem bem entendidas ${ }^{8}$, são a anandamida e o glicerol araquidonil (2-AG), cujas estruturas químicas estão representadas na Figura 7.

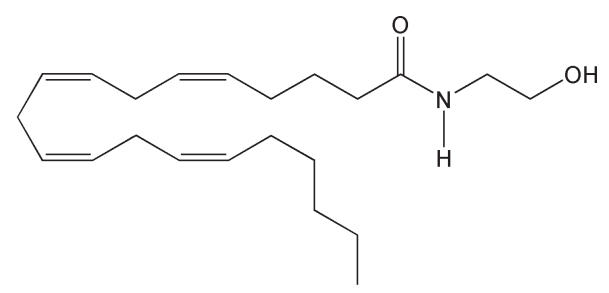

Anandamida

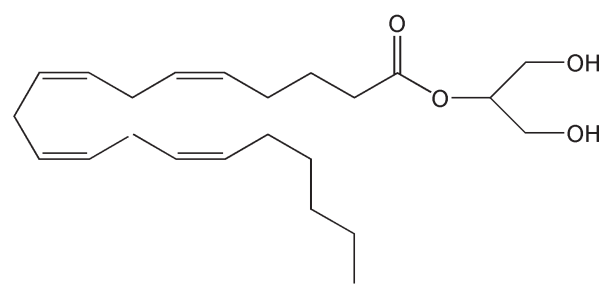

2-glicerol araquidonil (2-AG)

Figura 7. Estrutura química da anandamida e do 2-glicerol araquidonil $(2-A G)$

Inicialmente, a busca por um canabinóide endógeno foi baseada no fato de que sua estrutura química seria similar à estrutura do $\Delta^{9}$-THC ${ }^{37}$. Isto era razoável, pois o alvo desta busca seria uma outra "chave" que se encaixaria ao receptor canabinóide (conhecida como interação "chave-fechadura") ${ }^{38}$, ativando o sistema de mensagem celular. Assim sendo, muitos estudos foram realizados e uma das importantes descobertas na biologia dos canabinóides está relacionada à diferença estrutural entre o $\Delta^{9}$-THC e a anandamida ${ }^{39}$. Uma busca similar por opióides endógenos (endorfinas) também revelou que suas estruturas químicas eram muito diferentes dos opióides derivados de plantas, ou seja, ópio e morfina ${ }^{26}$.

Vários compostos com estruturas químicas bastante diferentes e que ativam os receptores canabinóides vêm sendo estudados ${ }^{22}$, mas os mecanismos de interação entre estes compostos e os receptores canabinóides ainda não são completamente conhecidos. Uma área de pesquisa considerada promissora, segundo a literatura, seria o planejamento de ligantes que ativariam os receptores canabinóides $\left(\mathrm{CB}_{1} \text { e } \mathrm{CB}_{2}\right)^{40}$. A seguir, serão discutidos alguns aspectos de um dos canabinóides endógenos mais estudados (anandamida).

\section{Anandamida}

O primeiro canabinóide endógeno descoberto foi o araquidoniletanolamina, conhecido como anandamida, palavra derivada do sânscrito ananda, que significa "felicidade". Comparada com o $\Delta^{9}$-THC, a anandamida apresenta afinidade moderada pelo receptor $\mathrm{CB}_{1}$ e é rapidamente metabolizada pelas amidases (enzimas que removem grupos amida $)^{40}$. Apesar de seu curto período de ação, a anandamida apresenta a maioria dos efeitos farmacológicos do $\Delta^{9}-\mathrm{THC}^{41}$.

A anandamida é formada a partir do ácido araquidônico e etanolamina. $\mathrm{O}$ ácido araquidônico é um precursor comum de um grupo de moléculas biologicamente ativas incluindo as prostaglandinas. Embora a anandamida possa ser sintetizada de várias formas, a obtenção fisiologicamente relevante parece ser a clivagem enzimática do N-araquidonil-fosfatidil-etanolamina (NAPE), que produz a anandamida e o ácido fosfatídico ${ }^{42}$. A anandamida foi encontrada em várias regiões do cérebro humano (hipocampo, estriado e cerebelo) onde os receptores $\mathrm{CB}_{1}$ são abundantes. Isto implica em um papel fisiológico dos canabinóides endógenos nas funções cerebrais controladas por estas áreas, mas concentrações substanciais de anandamida também são encontradas no tálamo (uma área do cérebro que apresenta poucos receptores $\left.\mathrm{CB}_{1}\right)^{43}$. Um fato interessante é que a anandamida também foi encontrada em outras regiões do corpo, tais como baço, que apresenta altas concentrações de receptores $\mathrm{CB}_{2}$ e coração, onde pequenas quantidades de anandamida foram detectadas ${ }^{44-47}$.

Em geral, a afinidade da anandamida por receptores canabinóides é somente $1 / 4$ a $1 \frac{1}{2}$ da afinidade apresentada pelo $\Delta^{9}-\mathrm{THC}^{48}$. Estas diferenças dependem das células ou tecidos que são utilizados para testes e das condições experimentais ${ }^{48}$. Além da anandamida, outros agonistas e antagonistas dos receptores canabinóides são bastante estudados ${ }^{16}$ e alguns exemplos são apresentados na Tabela 3.

A molécula de anandamida possui efeitos centrais (no cérebro) e periféricos (no restante do corpo $)^{49}$. A região cerebral onde a anandamida é produzida e as enzimas que a sintetizam ainda não são conhecidas ${ }^{26}$. Conhecendo-se esta informação, seria possível fornecer indícios importantes para o papel natural da anandamida e para o entendimento dos circuitos cerebrais nos quais ela atua como um neurotransmissor. A importância do conhecimento dos circuitos cerebrais que envolvem a anandamida (e outros ligantes canabinóides endógenos) está no fato de que estes circuitos são os elementos essenciais que regulam funções específicas do cérebro, tais como humor, memória e cognição ${ }^{50}$.

\section{Estudos da relação estrutura-atividade (SAR) de compostos canabinóides}

Devido ao grande interesse pelos efeitos causados pelos compostos presentes na Cannabis, vários trabalhos vêm sendo desenvolvidos com intuito de compreender melhor as relações entre estrutura química dos canabinóides e atividade biológica apresentada por esses compostos ${ }^{1,2,31,51-77}$. Algumas relações importantes entre propriedades estruturais/eletrônicas e atividade biológica de compostos canabinóides foram observadas em trabalhos anterio- 
Tabela 3. Agonistas e antagonistas dos receptores canabinóides

\begin{tabular}{l} 
Composto Agonistas (ativam os receptores) \\
\hline Compostos derivados da planta
\end{tabular}

\section{Canabinóides encontrados em animais}

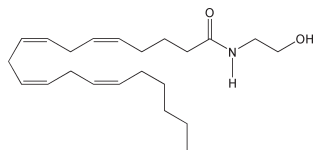

anandamida

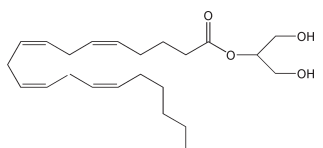

2-glicerol araquidonil (2-AG)

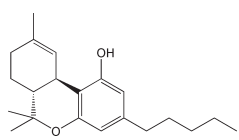

Dronabinol ( $\Delta^{9}$-THC sintético)

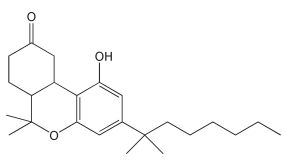

Nabilone
THC sintético. Comercializado nos EUA com o nome Marinol $^{\circledR}$, para náuseas associadas à quimioterapia e para pacientes com AIDS

Encontrada em animais (desde moluscos até mamíferos). Estrutura diferente dos canabinóides, está relacionada às prostaglandinas

Agonista endógeno, estruturalmente semelhante à anandamida. Mais abundante, mas menos potente que a anandamida

\section{)}

\section{Comercializado no Reino Unido com o nome Cesamet ${ }^{\circledR}$, para as mesmas indicações que o dronabinol.}

\begin{tabular}{l}
$\frac{\text { Composto }}{\text { Agonistas (ativam os receptores) }}$ \\
\hline$\underline{\text { Análogos ao THC }}$
\end{tabular}<smiles>CCCCCC(C)(C)C1CCC(C2CC(CCCO)CCC2O)C(O)C1</smiles>

Canabinóide sintético

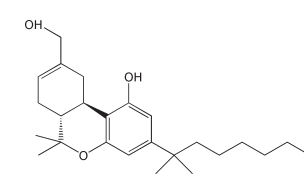

HU-210
$100-800$ mais potente que o THC

\section{Estrutura química diferente do THC ou anandamida}

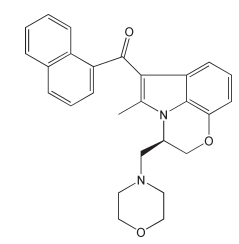

Estrutura química diferente dos canabinóides conhecidos, mas liga-se em ambos receptores canabinóides

WIN-55212

Antagonistas (bloqueiam os receptores)<smiles>CC1C(c2ccc(Cl)cc2)NC(c2ccc(O)c(O)c2)C1C(=O)C1CCCCC1</smiles>

SR 141716A

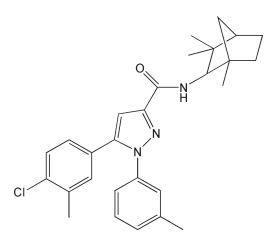

SR 144528
Antagonista sintético do $\mathrm{CB}_{1}$, desenvolvido em 1994
Antagonista sintético do $\mathrm{CB}_{2}$, desenvolvido em 1997 perda de atividade;

- a adição de um anel não-planar (anel A, Figura 8) ao sistema benzopirano nas posições 3 e 4 é importante para a atividade. Entretanto, a adição de um anel planar reduz a atividade;

- a adição de um substituinte volumoso na posição 4 do sistema benzopirano (Figura 8) também confere atividade à molécula; binóides ${ }^{1,2,31}$ :

- a presença do sistema benzopirano (ver estrutura na Figura 8) é uma condição importante, mas somente a presença deste sistema não confere atividade ao composto. $\mathrm{O}$ oxigênio presente no sistema benzopirano pode ser substituído por nitrogênio sem 
- uma variedade de substituintes pode ser introduzida ao anel A (Figura 8) sem perda de atividade. Sendo assim, o grupo metila na posição 9 no composto $\Delta^{9}$-THC não é essencial e pode ser substituído por uma hidroxila, uma hidroximetila ou uma cetona, sem perda de atividade. Mesmo a presença de dois substituintes diferentes no anel A (Figura 8), tais como um grupo metila na posição 9 e uma dupla ligação no anel A, ou uma hidroxila na posição 8 , mantém a atividade. Nos isômeros que contém a dupla ligação no anel A, a posição desta dupla ligação no átomo C9 favorece a presença de atividade $\left(\Delta^{9}>\Delta^{8}>\right.$ $\Delta^{6}$-THCs);

- a adição de um outro anel ao sistema benzopirano (Figura 8) pode ser substituída por um anel heterocíclico (por ex., tetraidropiridina) sem perda de atividade;

- esterificação de grupos fenólicos no anel C (Figura 8) mantém a atividade $\mathrm{e}$,

- o comprimento da cadeia lateral ligada ao anel $\mathrm{C}$ pode ser modificado sem perda de atividade, mas uma cadeia de três carbonos parece condição mínima para a atividade; ramificações nesta cadeia aumentam a potência. A adição de cadeias laterais ao anel $\mathrm{C}$ também pode ser realizada via um átomo de oxigênio (formando um éter) sem perda de atividade.<smiles>[R][X]1=NC2=C(C=NC(C)(C)O2)S(O)=N1</smiles>

Sistema benzopirano

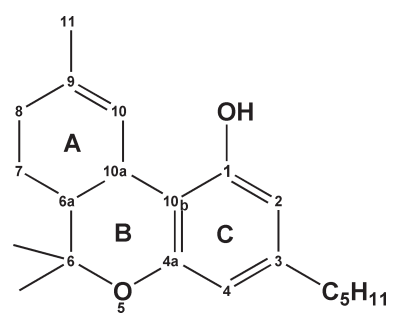

Sistema THC

Figura 8. Comparação das estruturas contendo os sistemas benzopirano e THC

\section{CONSIDERAÇÕES FINAIS}

Sabe-se que diversos compostos do tipo canabinoídes produzem algum tipo de propriedade terapêutica, mas também apresentam como efeito colateral propriedades psicotrópicas, limitando seu uso como medicamento. No entanto, estudos da relação entre estrutura química e atividade biológica têm sido realizados no sentido de modificar a estrutura química destes compostos a fim de suprimir sua psicoatividade. $\mathrm{O}$ estudo das relações estrutura-atividade (SAR) visa estabelecer relações entre descritores moleculares e atividade biológica em questão, colaborando na elucidação do mecanismo de ação dos compostos canabinóides.

Apesar de apresentar atividades terapêuticas comprovadas por pesquisas, o efeito colateral, isto é, a psicoatividade, ainda funciona como um obstáculo quanto à utilização da planta Cannabis com finalidade terapêutica. Como foi apresentado neste trabalho, é grande o interesse da comunidade científica sobre os compostos canabinóides, em virtude de apresentarem um grande espectro de atividades biológicas. Em parte, este interesse se deve ao fato da química da Cannabis ser extremamente complexa e ainda não estar perfeitamente compreendida, além das controvérsias relacionadas ao efeito colateral. Com o intuito de colaborar nesta discussão, este trabalho busca contribuir para o conhecimento dos possíveis processos envolvidos no uso terapêutico da Cannabis, visando o suporte para áreas de pesquisa sobre planejamento de novos compostos canabinóides que apresentem atividade terapêutica e ausência de atividade psicotrópica.

\section{AGRADECIMENTOS}

Ao CNPq e à FAPESP pelo auxílio financeiro.

\section{REFERÊNCIAS}

1. Mechoulam, R.; Marijuana: Chemistry, Pharmacology, Metabolism and Clinical Effects, Academic Press: New York, 1973.

2. Mechoulam, R.; Ben-Shabat, S.; Nat. Prod. Rep. 1999, 16, 131.

3. Julien, R. M.; A primer of drug action: a concise, nontechnical guide to the actions, uses and side effects of psychoactive drugs, W. H. Freeman and Company: New York, 1997.

4. Nahas, G. G.; Marihuana in science and medicine, Raven Press: New York, 1984.

5. Robson, P.; Br. J. Psychiatry 2001, 178, 107

6. Asthon, C. H.; Br. J. Psychiatry 2001, 178, 101.

7. Iversen, L.; Brain 2003, 126, 1252.

8. Kumar, R. N.; Chambers, W. A.; Pertwee, R. G.; Anaesthesia 2001, 56, 1059.

9. Williamson, E. M.; Evans, F. J.; Drugs 2000, 60, 1303.

10. Asthon, C. H.; Br. J. Anaesth. 1999, 83, 637.

11. Baker, D.; Pryce, G.; Giovannoni, G.; Thompson, A. J.; Lancet Neurol. 2003, 2, 291.

12. Petersen, R. C.; Marijuana Research Findings, Maryland, Department of Health and Human Services, 1980.

13. Mechoulam, R.; Hanus, L.; Chem. Phys. Lipids 2000, 108, 1.

14. http://www.unimed.com/prodindx.html, acessada em Fevereiro 2004.

15. http://www.rxmed.com/b.main/b2.pharmaceutical/b2.1.monographs/CPS$\% 20$ Monographs/CPS - \%20(General\%20Monographs-\%20C)/ CESAMET.html, acessada em Fevereiro 2004

16. Palmer, S. L.; Thakur, G. A.; Makriyannis, A.; Chem. Phys. Lipids 2002, $121,3$.

17. Hill, S. Y.; Goodwin, D. W.; Schwin, R.; Powell, B.; Am. J. Psychiat. 1974, $131,313$.

18. Clark, W. C.; Janal, M. N.; Zeidenberg, P.; Nahas, G. G.; J. Clin. Pharmacol. 1981, 21, 299S.

19. Brooks, J. W.; Current Anaesthesia \& Critical Care 2002, 13, 215.

20. Baker, D.; Pryce, G.; Croxford, J.; Brown, P.; Pertwee, R.; Hoffman, J.; Laynard, L.; Nature 2000, 2, 84.

21. Hepler, R. S.; Petrus, R. J.; J. Am. Med. Inf. Assoc. 1971, 217, 1392.

22. Tashkin, D. P.; Shapiro, B. J.; Lee, E. Y.; Harper, C. E.; New Engl. J. Med. 1976, 294, 125 .

23. Cunha, J. M.; Carlini, E. A.; Pereira, A. E.; Ramos, O. L.; Pimentel, C.; Gagliardi, R.; Sanvito, W. L.; Lander, N.; Mechoulam, R.; Pharmacology 1980, 21, 175.

24. Carlini, E. A.; Cunha, J. M.; J. Clin. Pharmacol. 1981, 21, 417S.

25. Hall, W.; Solowij, N.; Lancet 1998, 352, 1611.

26. Joy, J. E.; Watson, S. J.; Benson, J. A.; Marijuana and medicine: assessing the science base, National Academy Press: New York, 1999.

27. DiMasi, J. A.; Hansen, R. W.; Grabowski, H. G.; J. Health Econ. 2003 , 22, 151 .

28. Pratt, W. B.; Taylor, P.; Principles of drug action: the basis of pharmacology, Churchill Livingstone: New York, 1990.

29. Iversen, L. L.; Chapman, V.; Curr. Opin. Pharmacol. 2002, 2, 50.

30. Kuntz, M. J.; Pain 1986, 27, 30.

31. Razdan, R. K.; Pharmacol. Rev. 1986, 38, 75.

32. Kalso, E.; Br. Med. J. 2001, 323, 2.

33. Matsuda, L. A.; Lolait, S. J.; Brownstein, M. J.; Nature 1990, 346, 561.

34. Howlett, A. C.; Qualy, J. M.; Khachatrian, L. L.; Mol. Pharmacol. 1986, $29,307$.

35. Griffin, G.; Williams, S.; Aung, M. M.; Razdan, R. K.; Martin, B. R.; Abood, M. E.; Br. J. Pharmacol. 2001, 132, 525. 
36. Howlett, A. C.; Prostaglandins Other Lipid Mediat. 2002, 68, 619.

37. Rogers-Evans, M.; Alanine, A. I.; Bleicher, K. H.; Kube, D.; Schneider, G.; QSAR Comb. Sci. 2004, 23, 426.

38. Fischer, E. H.; Dictionary of Scientific Biography, 1981, vol. 5, p.1-5; Erlich, P.; Lancet 1913, 2, 445.

39. Cravatt, B. F.; Demarest, K.; Patricelli, M. P.; Proc. Natl. Acad. Sci. U.S.A 2001, 98, 9371 .

40. Hilliard, C. J.; Manna, S.; Greenberg, M. J.; Dicamelli, R.; Ross, R. A.; Stevenson, L. A.; Murphy, V.; Pertwee, R. G.; Campbell, W. B.; J. Pharmacol. Exp. Ther. 1999, 289, 1427.

41. Devane, W. A.; Hanus, L.; Breuer, A.; Science 1992, 258, 1946.

42. Berdyshev, E. V.; Boichot, E.; Lagente, V.; J. Lipid Mediators Cell Signalling 1996, 15, 49.

43. DiMarzo, V.; Fontana, A.; Cadas, H.; Nature 1994, 372, 686.

44. Pop, E.; Curr. Opin. Chem. Biol. 1999, 3, 418.

45. Ameri, A.; Prog. Neurobiol. 1999, 58, 315.

46. Fowler, C.; Brain Res. Rev. 2003, 41, 26.

47. Howlett, A. C.; Neurobiol. Dis. 1998, 5, 405.

48. Smith, P. B.; Compton, D. R.; Welch, S. P.; Razdan, J. K.; Mechoulam, R.; Martin, B. R.; J. Pharmacol. Exp. Ther. 1994, 270, 219.

49. DiMarzo, V.; Breivogel, C. S.; Tao, Q.; J. Neurochem. 2000, 75, 2434

50. Hillard, C. J.; Campbell, W. B.; J. Lipid Res. 1997, 38, 2383.

51. Tarzia, G.; Duranti, A.; Tontini, A.; Spadoni, G.; Mor, M.; Rivara, S.; Plazzi, P. V.; Kathuria, S.; Piomelli, D.; Bioorg. Med. Chem. 2003, 11, 3965.

52. Palmer, S. L.; Khanolkar, A. D.; Makriyannis, A.; Curr. Pharm. Des. 2000, $6,1381$.

53. Seltzman, H. H.; Curr. Med. Chem. 1999, 6, 685.

54. Carlini, E. A.; Santos, M.; Claussen, U.; Bieniek, D.; Korte, F.; Psychopharmacology 1970, 18, 82.

55. Leite, J. R.; Carlini, E. A.; Lander, N.; Mechoulam, R.; Pharmacology 1982, 24, 141.

56. Reggio, P. H.; Curr. Pharm. Des. 2003, 9, 1607.

57. Barnett-Norris, J.; Hurst, D. P.; Lynch, D. L.; Guarnieri, F.; Makriyannis, A.; Reggio, P. H.; J. Med. Chem. 2002, 45, 3649.

58. Rhee, M. H.; Vogel, Z.; Barg, J.; Bayewitch, M.; Levy, R.; Hanus, L.; Breuer, A.; Mechoulam, R.; J. Med. Chem. 1997, 40, 3228.
59. Sheskin, T.; Hanus, L.; Slager, J.; Vogel, Z.; Mechoulam, R.; J. Med. Chem. 1997, 40, 659 .

60. Glaser, R.; Adin, I.; Mechoulam, R.; Heterocycles 1994, 39, 867.

61. Martin, B. R.; Compton, D. R.; Thomas, B. F.; Prescott, W. R.; Little, P. J.; Razdan, R. K.; Johnson, M. R.; Melvin, L. S.; Mechoulam, R.; Ward, S. J.; Pharmacol. Biochem. Behav. 1991, 40, 471.

62. Howlett, A. C.; Champion, T. M.; Wilken, G. H.; Mechoulam, R.; Neuropharmacology 1990, 29, 161

63. Mechoulam, R.; Lander, N.; Varkony, T. H.; Kimmel, I.; Becker, O.; Benzvi, Z.; Edery, H.; Porath, G.; J. Med. Chem. 1980, 23, 1068.

64. Reggio, P. H.; Prostaglandins, Leukotrienes Essent. Fatty Acids 2002, 66, 143.

65. Reggio, P. H.; Wang, T. S.; Brown, A. E.; Fleming, D. N.; Seltzman, H. H.; Griffin, G.; Pertwee, R. G.; Compton, D. R.; Abood, M. E.; Martin, B. R.; J. Med. Chem. 1997, 40, 3312.

66. Reggio, P. H.; Int. J. Quantum Chem. 1992, 44, 165.

67. Reggio, P. H.; Seltzman, H. H.; Compton, D. R.; Prescott, W. R.; Martin, B. R.; Mol. Pharmacol. 1990, 38, 854.

68. Reggio, P. H.; Greer, K. V.; Cox, S. M.; J. Med. Chem. 1989, 32, 1630.

69. Keimowitz, A. R.; Martin, B. R.; Razdan, R. K.; Crocker, P. J.; Mascarella, S. W.; Thomas, B. F.; J. Med. Chem. 2000, 43, 59.

70. Thomas, B. F.; Adams, I. B.; Mascarella, S. W.; Martin, B. R.; Razdan, R. K.; J. Med. Chem. 1996, 39, 471

71. Compton, D. R.; Rice, K. C.; Decosta, B. R.; Razdan, R. K.; Melvin, L. S.; Johnson, M. R.; Martin, B. R.; J. Pharmacol. Exp. Ther. 1993, 265 , 218.

72. Da Silva, A. B. F.; Trsic, M.; J. Mol. Struct. (Theochem) 1995, 356, 247.

73. Da Silva, S. L.; Arroio, A.; Da Silva, A. B. F.; Trsic, M.; J. Mol. Struct. (Theochem) 1998, 441, 97.

74. Honório, K. M.; Freitas, L. G.; Trsic, M.; Da Silva, A. B. F.; J. Mol. Struct. (Theochem) 2001, 538, 99.

75. Honório, K. M.; Da Silva, A. B. F.; J. Mol. Struct. (Theochem) 2002, 578, 111.

76. Honório, K. M.; Da Silva, A. B. F.; J. Mol. Model. 2005, 11, 200.

77. Arroio, A.; Honório, K. M.; Da Silva, A. B. F.; J. Mol. Struct. (Theochem) 2004, 709, 223. 